\title{
Thoracic Disc Herniation Manifesting as Abdominal Pain Alone Associated with Thoracic Radiculopathy
}

\author{
Motonori Ishii, ${ }^{1}$ Yusuke Nishimura, ${ }_{1}^{1}$ Masahito Hara, ${ }^{2}$ Kaoru Eguchi, ${ }^{1}$ Yoshitaka Nagashima, \\ Takayuki Awaya, ${ }^{1}$ Ryo Ando, ${ }^{1}$ Shoichi Haimoto, ${ }^{1}$ and Toshihiko Wakabayashi ${ }^{1}$
}

\begin{abstract}
Symptomatic thoracic disc herniation (TDH) with thoracic radiculopathy alone is an extremely rare condition. Here, we report a rare case of TDH in a 52-year-old man who presented with medically refractory severe right flank pain. Based on pain distribution, pain intensity changes according to truncal position, ineffectiveness of intercostal nerve block, and radiological findings, his pain was determined to be caused by TDH at T9-10 level. Symptomatic TDH often requires invasive surgery. However, TDH with radiculopathy alone can be treated via a posterior approach without spinal cord manipulation or spinal fusion. We could eliminate the pain by removing TDH with hemilaminectomy and microdiscectomy using an O-arm-based navigation system.
\end{abstract}

Keywords: thoracic disc herniation, thoracic radiculopathy, intercostal neuralgia, abdominal wall pain, posterior approach

\section{Introduction}

Symptomatic thoracic disc herniation (TDH) is estimated to occur with a frequency of 1 per million each year. ${ }^{1,2}$ The commonest location of TDH is central or centrolateral to the spinal canal below the T7 level. When TDH occurs in these positions, it is extremely rare that radicular pain is the only symptom. ${ }^{1)} \mathrm{A}$ patient who only complains of radiculopathy, such as abdominal pain, might be mistakenly diagnosed with psychogenic pain, intercostal nerve entrapment caused by muscle stiffness and truncal position or visceral disease without history of trauma, prior surgery or skin infection, thereby resulting in the risk of downgrading the severity of the disease or undergoing unnecessary invasive procedures. ${ }^{3)}$ We report here a rare case of a 52-year-old male, who presented with unilateral severe flank pain with a previous diagnosis of intercostal neuralgia after visiting different hospitals. We evaluated that his pain derived from thoracic radiculopathy caused by TDH and successfully treated him surgically. In the discussion section, we also review the literature of TDH presenting with thoracic radiculopathy to discuss how to make a correct diagnosis and provide adequate treatment.

\footnotetext{
${ }^{1}$ Department of Neurosurgery, Nagoya University School of Medicine, Nagoya, Aichi, Japan

${ }^{2}$ Department of Neurosurgery, Aichi Medical University, Nagakute, Aichi, Japan

Received: November 6, 2019; Accepted: February 3, 2020

Online September 15, 2020

Copyright $₫ 2020$ by The Japan Neurosurgical Society

This work is licensed under a Creative Commons Attribution-

NonCommercial-NoDerivatives International License.
}

\section{Case Report}

A 52-year-old male was referred to us with medically refractory severe right flank pain lasting for 1 year. The pain radiated from the back to the umbilics on the right side in the T9 dermatomal distribution, which was relieved by truncal extension and deteriorated by truncal flexion. He was working as a security guard and had to put a lumbar brace on to maintain the truncal extension posture and avoid daily excruciating pain. He had visited multiple medical institutions and was unsuccessfully prescribed with various type of pain killers. He also underwent several intercostal nerve block procedures performed by anesthetists with little effect. Otherwise, he was neurologically intact, without weakness and sensory disturbance in the four limbs. His past medical history was unremarkable, and there was no history of trauma, prior surgery or skin infection. Thoracic spine magnetic resonance imaging (MRI) showed a centrolateral to foraminal TDH at the T9-10 level (Fig. 1). Thoracic spine computed tomography (CT) showed intraforaminal calcification, indicating the presence of calcified disc herniation (Fig. 2). We evaluated that his symptoms were compatible with T9 thoracic radiculopathy caused by TDH, based on his pain distribution, characteristic pain intensity changes in accordance with his truncal position, and the corresponding radiological imaging findings. We also judged that the prior intercostal nerve block procedures had been ineffective, since the pathology was located far proximal to the injection site for the nerve block. The patient declined to undergo additional nerve root block, such as T9 nerve root block, so we proceeded to perform a thoracic hemilaminectomy and microdiscectomy at T9-10 level via a posterior approach, following the patient's wish. We used an O-arm-based navigation system to control the scope of facet joint resection up to $50 \%$. The herniated disc was successfully removed, taking the pressure off from the affected T9 nerve root (Figs. 3D and 3E). The surgery was successful, without any neurological complications and his pain disappeared immediately after surgery. Postoperative CT showed that more than half of the facet joint was preserved (Figs. 3A-3C). At his postoperative 1-year follow-up, he is completely free from the pain.

\section{Discussion}

There is a wide variety of signs and symptoms caused by TDH. Quint et al. ${ }^{4}$ reported that $92 \%$ of TDH patients complained of pain, and more than half of them complained of radicular pain. In their review of literature, Elhadi et al. $\left.{ }^{5}\right)$ reported that $39.5 \%$ of the $488 \mathrm{TDH}$ patients showed 

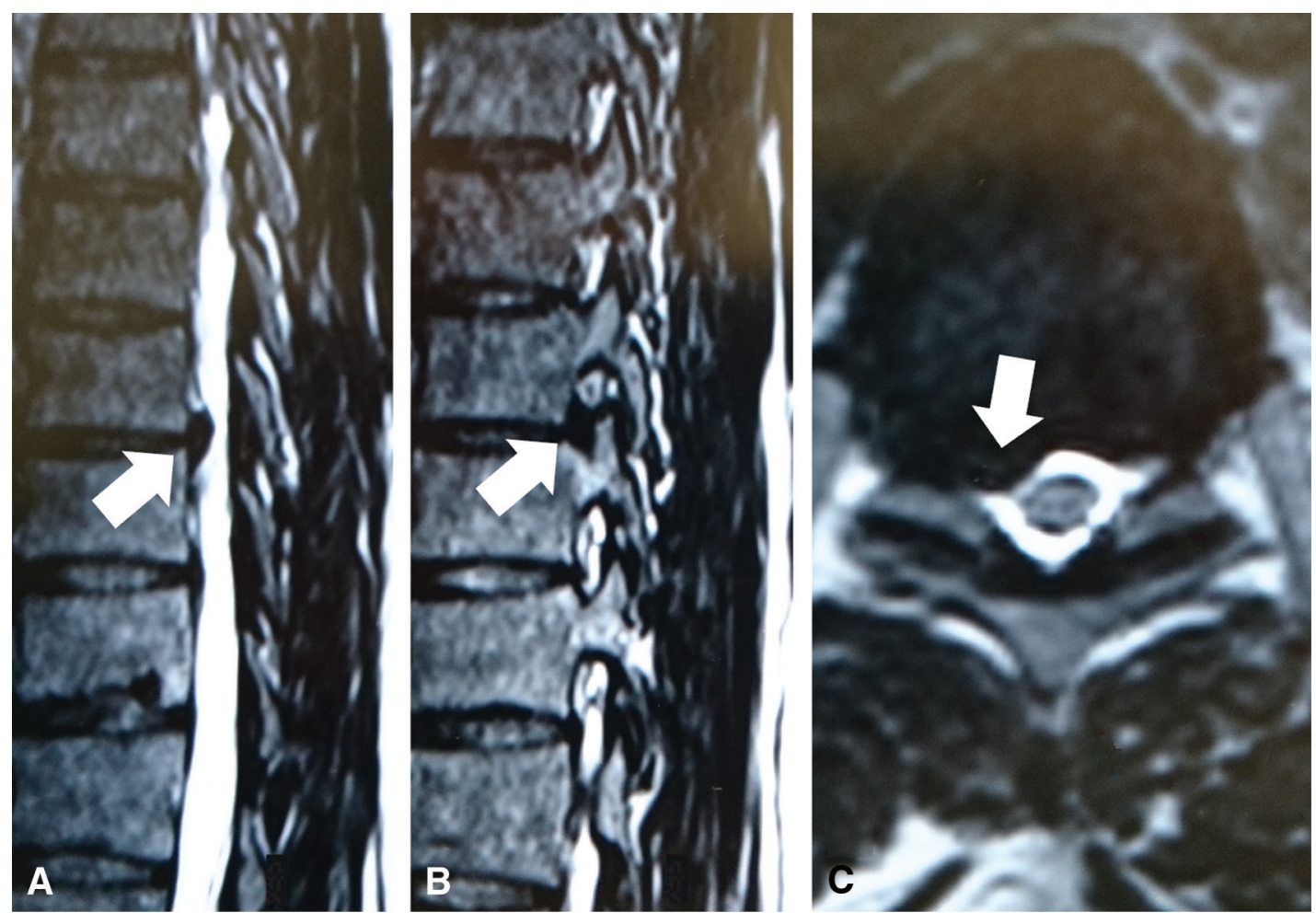

Fig. 1 Sagittal (A, B) and axial (C) section of T2-weighted MRI showing centrolateral to foraminal disc herniation compressing the T9 nerve root. Arrows indicate the herniated disc. MRI: magnetic resonance imaging.
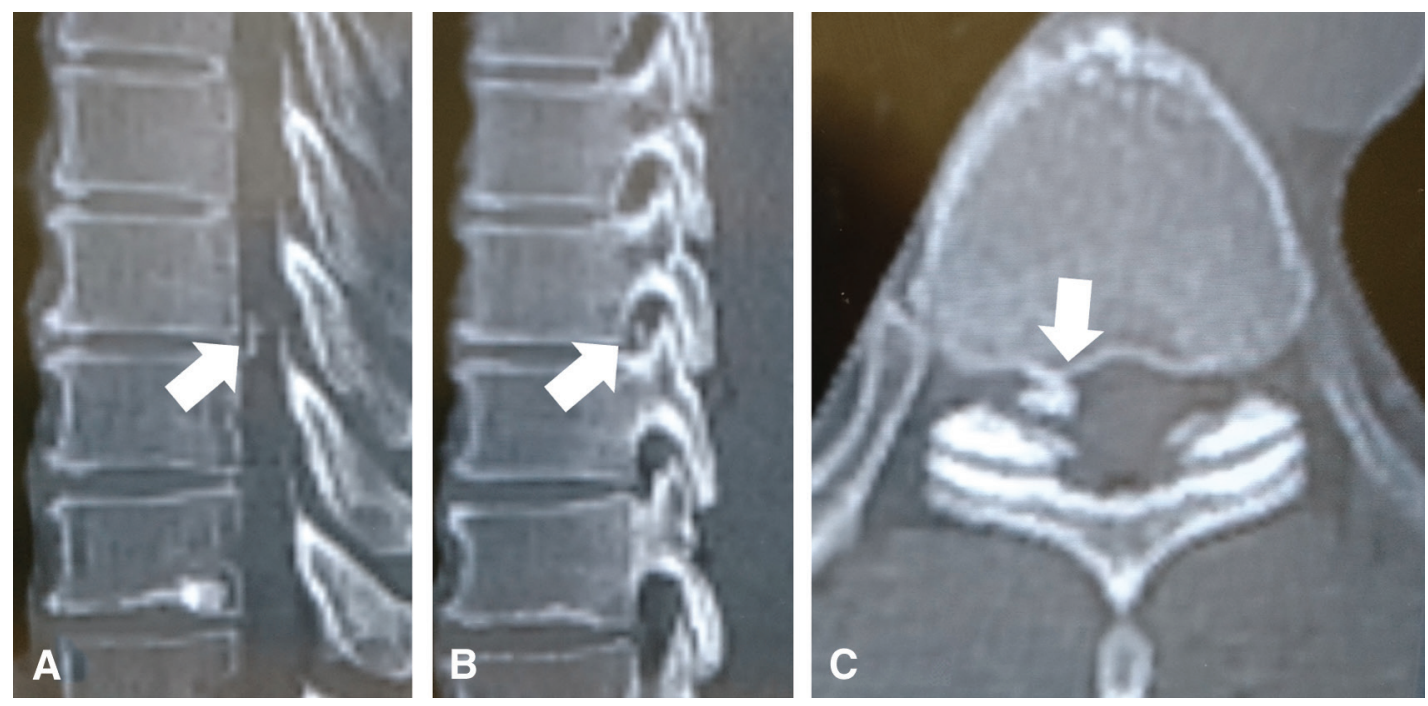

Fig. 2 Sagittal (A and $\mathbf{B})$ and axial section (C) of CT showing the calcified TDH and narrowing of the intervertebral foramen (B). Arrows indicate the calcified TDH. CT: computed tomography, TDH: thoracic disc herniation.

radiculopathy. Radicular pain itself is not uncommon for TDH. However, it is extremely rare that radiculopathy is the only symptom. ${ }^{1)}$ To the best of our knowledge, there are only 11 cases in the literature reporting a TDH with radiculopathy alone, such as chest, abdominal pain, and abdominal muscle weakness (Table 1). ${ }^{3,6-14)}$ Radiculopathy of TDH could result in abdominal muscle weakness and pain along with the thoracic spinal dermatomal distribution, occasionally accompanied by nausea and vomiting, which may easily be misdiagnosed with intra-abdominal or pelvic pathology. ${ }^{15,16)}$ Some of the reported cases underwent unnecessary invasive procedures, such as laparoscopy, before the correct diagnosis of TDH was made. ${ }^{3)}$ While a thorough visceral test should be required in these cases, when a diagnosis of visceral disease 

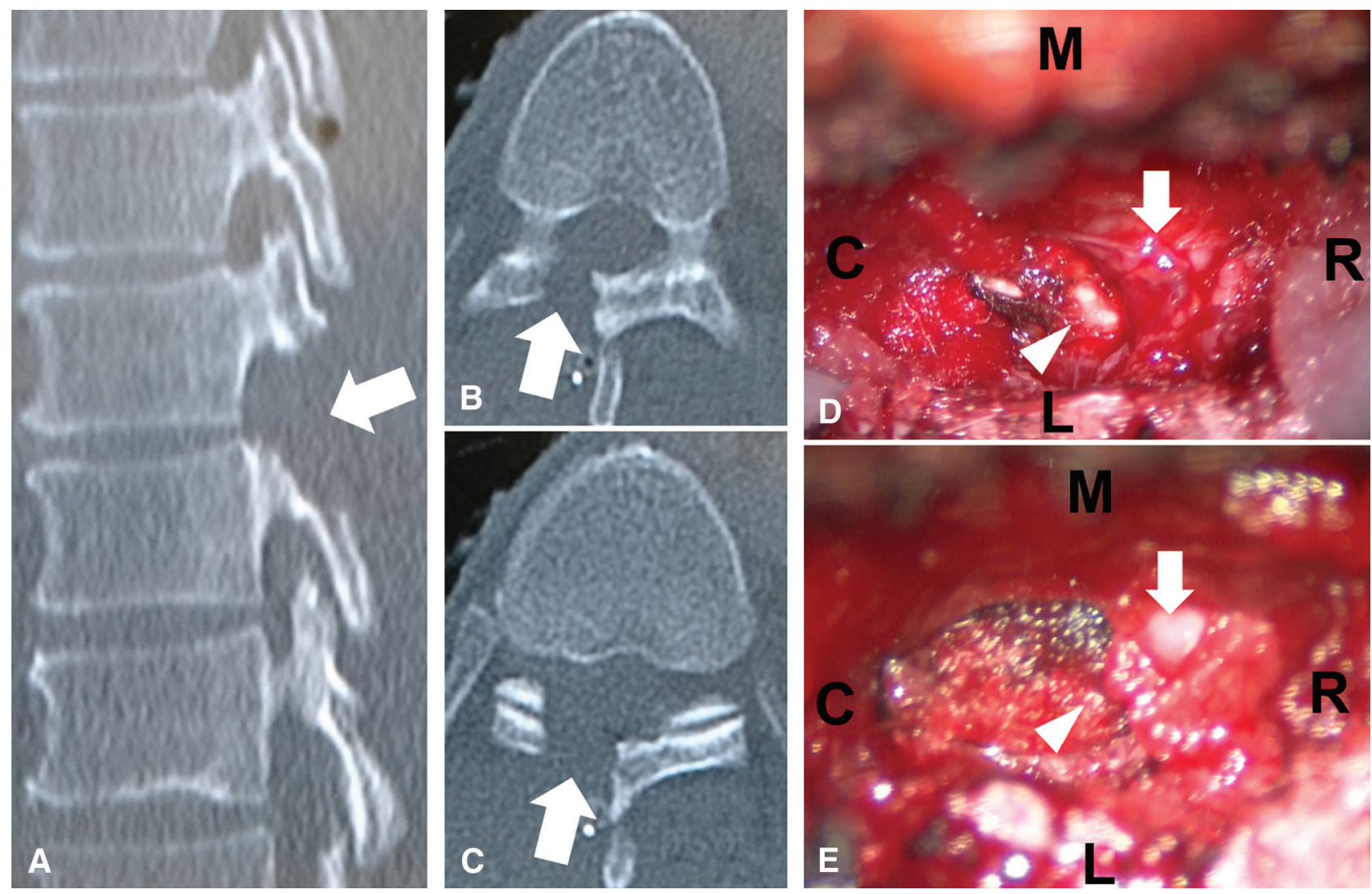

Fig. 3 Postoperative CT images showing the location of laminectomy (arrow) and decompressed intervertebral foramen (A). Axial CT images show that more than half of the facet joint was preserved $(\mathbf{B}, \mathbf{C})$. D showed T9 disc herniation. T9 nerve root (arrow) was severely compressed by the disc TDH (arrowhead) and displaced rostrally, looking congested (E). The pressure was successfully taken off from the T9 root (arrow) and TDH was nicely removed (arrowhead). C: caudal side, CT: computed tomography, M: medial side, L: lateral side, R: rostral side, TDH: thoracic disc herniation.

is ruled out, we need to differentiate abdominal wall pain. Abdominal wall pain includes intercostal neuralgia, myofascial pain, and visceral disease in which inflammation spreads to the peritoneum other than thoracic radiculopathy. Srinivasan et al. ${ }^{17)}$ reported the usefulness of Carnett's test (judged as positive if the tenderness exacerbates when the abdominal wall is tensed) in differentiating abdominal wall pain from visceral diseases. They described that chronic abdominal wall pain can be diagnosed with $85 \%$ sensitivity and $97 \%$ specificity if any of the following criteria are satisfied with pain lasting more than 1 month: (1) very localized pain that can be covered with a fingertip and (2) fulfillment of any of the following criteria: fixed location of tenderness with superficial tenderness; point tenderness less than $2.5 \mathrm{~cm}$; or positive Carnett's test. Routine needle EMG is also helpful for the assessment of nerve root impairment, disclosing positive sharp waves or fibrillation potentials in muscles on the radiculopathy level. ${ }^{12)}$ Carnett's test was positive in the present case, while invasive tests such as EMG was not performed since the diagnosis could be made based on radiological findings and clinical symptoms. Intercostal neuralgia is the most common in the abdominal wall pain, which is usually caused by herpes zoster, direct injury to the nerve or nerve entrapment associated with iatrogenic neuroma or prior surgery and deteriorates on coughing, sneezing, and deep inspiration. ${ }^{18)}$ It is sometimes difficult to identify the thoracic radiculopathy as a cause of intercostal neuralgia. In the present case, the intercostal nerve block had almost no effect on the pain, indicating far more proximal lesion to the site of nerve block. Furthermore, the pain distribution corresponded to a dermatomal distribution at the index level and the intensity of pain varied in accordance with spinal movements. Several reports described that the radiculopathy caused by TDH is aggravated with lateral bending, rotation, flexion of the trunk, ${ }^{19)}$ and supine or side-lying position. ${ }^{14,20)}$ The patient in this report exhibited pain relief only when the trunk was extended when standing with a rigid lumbar brace. We think that reduction of intervertebral disc pressure by extension and/or stabilization of functional motion unit of T9-10 by rigid lumbar brace led to temporary pain relief. Furthermore, we observed a clearly calcified TDH squeezing the T9 nerve root on MRI, which was consistent with his pain distribution. These findings prompted us to consider that his pain originated from the thoracic spine.

The surgical indications and surgery of choice for treating TDH should be determined on a case-by-case basis. Surgical treatment is indicated in the case of medically refractory pain or progressive myelopathy. ${ }^{21,22)}$ Several surgical approaches 
Table 1 Summary of thoracic disc herniation cases with radiculopathy alone

\begin{tabular}{|c|c|c|c|c|c|c|}
\hline Authors and year & $\begin{array}{l}\text { Age (years)/ } \\
\text { sex }\end{array}$ & Level & Location & Symptoms & $\begin{array}{l}\text { Wrong site surgery or } \\
\text { invasive examination }\end{array}$ & Treatment \\
\hline $\begin{array}{l}\text { Whitcomb DC et al., } \\
1995\end{array}$ & $\mathrm{NS} / \mathrm{F}$ & $\mathrm{T} 7-8$ & NS & Epigastric pain & Pancreatico-jejunostomy & Microdiscectomy \\
\hline Xiong Y et al., 2001 & $32 / \mathrm{F}$ & T9-10 & Centrolateral & $\begin{array}{l}\text { Abdominal and pelvic } \\
\text { pain }\end{array}$ & Laparoscopy & $\begin{array}{l}\text { Laminectomy and } \\
\text { discectomy }\end{array}$ \\
\hline $\begin{array}{l}\text { Stetkarova I et al., } \\
2007\end{array}$ & $50 / \mathrm{F}$ & T12-L1 & Centrolateral & $\begin{array}{c}\text { Flank pain and muscle } \\
\text { weakness }\end{array}$ & NA & Medication \\
\hline $\begin{array}{l}\text { Stetkarova I et al., } \\
2007\end{array}$ & $34 / \mathrm{M}$ & $\begin{array}{l}\text { T10-11, } \\
\text { T11-12 }\end{array}$ & Centrolateral & Lower abdominal pain & NA & Root nerve injection \\
\hline $\begin{array}{l}\text { LaBan MM et al., } \\
2007\end{array}$ & $75 / \mathrm{M}$ & T12-L1 & Centrolateral & $\begin{array}{l}\text { Abdominal muscle } \\
\text { weakness, and flank and } \\
\text { abdominal pain }\end{array}$ & NA & $\begin{array}{l}\text { Split-table intermittent } \\
\text { pelvic tractionthermal } \\
\text { therapy }\end{array}$ \\
\hline $\begin{array}{l}\text { Papadakos N et al., } \\
2009\end{array}$ & $52 / \mathrm{F}$ & $\mathrm{T} 11-12$ & Centrolateral & $\begin{array}{l}\text { Left loin pain radiating to } \\
\text { groin }\end{array}$ & $\begin{array}{l}\text { Laparoscopy, } \\
\text { colonoscopy, and } \\
\text { cystoscopy }\end{array}$ & Microdiscectomy \\
\hline Baranto A et al., 2009 & $24 / \mathrm{M}$ & $\begin{array}{l}\text { T2-3, } \\
\text { T3-4 }\end{array}$ & Centrolateral & Chest pain & NA & Physiotherapy \\
\hline $\begin{array}{l}\text { Hafsteinsdottir B } \\
\text { et al., } 2012\end{array}$ & $59 / \mathrm{M}$ & $\mathrm{T} 11-12$ & Centrolateral & Right flank pain & NA & Conservating therapy \\
\hline $\begin{array}{l}\text { Srinivasan V et al., } \\
2012\end{array}$ & $72 / \mathrm{M}$ & T9-10 & Centrolateral & Left-sided chest pain & NA & Operation \\
\hline $\begin{array}{l}\text { Piccirilli M et al., } \\
2012\end{array}$ & $36 / F$ & $\mathrm{~T} 7-8$ & Centrolateral & $\begin{array}{l}\text { Subscapular right-sided } \\
\text { dorsal pain }\end{array}$ & NA & Medication \\
\hline Sari H et al., 2016 & 38/M & $\mathrm{T} 7-8$ & Centrolateral & $\begin{array}{l}\text { Subscapular left-sided } \\
\text { dorsal radiating pain, and } \\
\text { paresthesia radiating to } \\
\text { left chest wall }\end{array}$ & NA & $\begin{array}{l}\text { Medication and } \\
\text { physical therapy }\end{array}$ \\
\hline Present case & $52 / \mathrm{M}$ & Т9-10 & Centrolateral & Right flank pain & NA & Microdiscectomy \\
\hline
\end{tabular}

NA: not applicable, NS: not specified.

have been suggested for the removal of TDH without manipulating the spinal cord. These procedures are classified into posterolateral, posterior, lateral transthoracic approach, and less invasive techniques using image-guided thoracoscopy, endoscope, and novel retractor system. ${ }^{23-26)}$ Because the herniated disc was not centrally located in our case, we could successfully remove TDH without spinal cord manipulation via the posterior approach without spinal fusion. Fusion may be avoided if the lateral portion of the facet joint is preserved. ${ }^{21,22)}$ As reported by Kim et al. ${ }^{27)}$ and Schlenzka et al., ${ }^{28)}$ an O-arm-based navigation system helped to firmly identify the spinal anatomy. We could determine the extent of the bone resection and muscles dissection with the image guidance technique resulting in preservation of more than half of the facet joint. O-arm-based navigation system allows us to minimize muscle invasion and damage to medial branch of posterior ramus of the spinal nerves. Furthermore, we could easily identify the index level with this system even for hard-to-localize middle to upper thoracic levels. We could eventually preserve more than half of the facet joint with the image guidance technique. Postoperative $\mathrm{CT}$ showed that the bone resection had been performed as planned, resulting in no indication of spinal instability.

\section{Conclusion}

We report here a patient manifesting abdominal pain due to radiculopathy caused by TDH at the T9-10 level. If abdominal pain alone is observed, it is necessary to investigate the characteristics of pain and considering the possible presence of TDH. TDH with only thoracic radiculopathy can be treated with less invasive surgical procedure, without spinal fusion.

\section{Conflicts of Interest Disclosure}

The authors report no conflict of interest concerning the materials or methods used in this study or the findings specified in this paper. The authors have no personal, financial, or institutional interest in any of the drugs, materials, or devices described in this manuscript.

\section{References}

1) Arce CA, Dohrmann GJ: Thoracic disc herniation. Improved diagnosis with computed tomographic scanning and a review of the literature. Surg Neurol 23: 356-361, 1985 
2) Stillerman CB, Chen TC, Couldwell WT, Zhang W, Weiss MH: Experience in the surgical management of 82 symptomatic herniated thoracic discs and review of the literature. J Neurosurg 88: 623-633, 1998

3) Papadakos N, Georges H, Sibtain N, Tolias CM: Thoracic disc prolapse presenting with abdominal pain: case report and review of the literature. Ann R Coll Surg Engl 91: W4-W6, 2009

4) Quint U, Bordon G, Preissl I, Sanner C, Rosenthal D: Thoracoscopic treatment for single level symptomatic thoracic disc herniation: a prospective followed cohort study in a group of 167 consecutive cases. Eur Spine J 21: 637-645, 2012

5) Elhadi AM, Zehri AH, Zaidi HA, et al.: Surgical efficacy of minimally invasive thoracic discectomy. J Clin Neurosci 22: 1708-1713, 2015

6) Baranto A, Börjesson M, Danielsson B, Hellström M, Swärd L: Acute chest pain in a top soccer player due to thoracic disc herniation. Spine 34: E359-362, 2009

7) Hafsteinsdottir B, Olafsson E: Thoracal radiculopathy owing to disc herniation. Arch Neurol 69: 1080-1081, 2012

8) LaBan MM, Gorin G: A thoracic disc herniation presenting as an abdominal hernia. Am J Phys Med Rehabil 86: 601, 2007

9) Piccirilli M, Lapadula G, Caporlingua F, Martini S, Santoro A: Spontaneous regression of a thoracic calcified disc herniation in a young female: a case report and literature review. Clin Neurol Neurosurg 114: 779-781, 2012

10) Sari H, Misirlioglu TO, Palamar D: Regression of a symptomatic thoracic disc herniation with a calcified intervertebral disc component. Acta Orthop Traumatol Turc 50: 698-701, 2016

11) Srinivasan V, Kesler H, Johnson M, Dorfman H, Walter K: Tophaceous pseudogout of the thoracic spine. Acta Neurochir (Wien) 154: 747-750; discussion 750, 2012

12) Stetkarova I, Chrobok J, Ehler E, Kofler M: Segmental abdominal wall paresis caused by lateral low thoracic disc herniation. Spine 32: E635-639, 2007

13) Whitcomb DC, Martin SP, Schoen RE, Jho HD: Chronic abdominal pain caused by thoracic disc herniation. Am J Gastroenterol 90: 835-837, 1995

14) Xiong $Y$, Lachmann E, Marini $S$, Nagler W: Thoracic disk herniation presenting as abdominal and pelvic pain: a case report. Arch Phys Med Rehabil 82: 1142-1144, 2001
15) Rohde RS, Kang JD: Thoracic disc herniation presenting with chronic nausea and abdominal pain. J Bone Joint Surg Am 86: 379381, 2004

16) Shirzadi A, Drazin D, Jeswani S, Lovely L, Liu J: Atypical presentation of thoracic disc herniation: Case series and review of the literature. Case Rep Orthop 2013: 621476, 2013

17) Srinivasan R, Greenbaum DS: Chronic abdominal wall pain: a frequently overlooked problem. Practical approach to diagnosis and management. Am J Gastroenterol 97: 824-830, 2002

18) Dureja GP: Intercostal Neuralgia: A review. J Neurol Transl Neurosci 5: 1076-1076, 2017

19) Kato K, Yabuki S, Otani K, et al.: Unusual chest wall pain caused by thoracic disc herniation in a professional baseball pitcher. Fukushima J Med Sci 62: 64-67, 2016

20) Ozturk C, Tezer M, Sirvanci M, Sarier M, Aydogan M, Hamzaoglu A: Far lateral thoracic disc herniation presenting with flank pain. Spine $J 6$ : 201-203, 2006

21) Bouthors C, Benzakour A, Court C: Surgical treatment of thoracic disc herniation: an overview. Int Orthop 43: 807-816, 2019

22) Court C, Mansour E, Bouthors C: Thoracic disc herniation: Surgical treatment. Orthop Traumatol Surg Res 104: S31-S40, 2018

23) Bordon G, Burguet Girona S: Experience in the treatment of thoracic herniated disc using image-guided thorascopy. Rev Esp Cir Ortop Traumatol 61: 124-129, 2017

24) Cho JY, Lee SH, Jang SH, Lee HY: Oblique paraspinal approach for thoracic disc herniations using tubular retractor with robotic holder: a technical note. Eur Spine J 21: 2620-2625, 2012

25) Deviren V, Kuelling FA, Poulter G, Pekmezci M: Minimal invasive anterolateral transthoracic transpleural approach: a novel technique for thoracic disc herniation. A review of the literature, description of a new surgical technique and experience with first 12 consecutive patients. J Spinal Disord Tech 24: E40-48, 2011

26) Wagner R, Telfeian AE, Iprenburg M, et al.: Transforaminal Endoscopic Foraminoplasty and Discectomy for the Treatment of a Thoracic Disc Herniation. World Neurosurg 90: 194-198, 2016

27) Kim JS, Eun SS, Prada N, Choi G, Lee SH: Modified transcorporeal anterior cervical microforaminotomy assisted by O-arm-based navigation: a technical case report. Eur Spine J 20 Suppl 2: S147-152, 2011

28) Schlenzka D, Laine T, Lund T: Computer-assisted spine surgery. Eur Spine J 9 Suppl 1: S57-64, 2000

Corresponding author:

Yusuke Nishimura, MD, PhD, Department of Neurosurgery, Nagoya University School of Medicine, 65 Tsurumaicho, Showa-ku, Nagoya, Aichi 466-8550, Japan.

$\triangle$ yusuken0411@med.nagoya-u.ac.jp 